Europe's Journal of Psychology, 7(4), pp. 664-685

www.ejop.org

\title{
Relation between human resource development climate and employee engagement: Results from India
}

\author{
Richa Chaudhary \\ Santosh Rangnekar \\ Mukesh Barua \\ Department of Management Studies, Indian institute of Technology
}

\begin{abstract}
In a recent analysis (July 29, 2010) Hewitt Associates have reported a steady decline in the global employee engagement levels. According to the report this is the largest drop in the engagement levels that has been observed in the past 15 years. This clearly highlights the need for some concrete mechanism to improve the engagement levels of the employees in organizations. In response to the dire need for organizations to increase engagement levels of employees, the importance of the human resource development (HRD) climate cannot be overlooked. The purpose of this study is to explore the impact of HRD Climate on employee engagement in select business organizations in Indian. An attempt is made to closely examine the interrelationship between factors of HRD Climate and employee engagement. The study was conducted on 85 business executives from both private and public sector manufacturing and service firms in India. Data was analyzed using correlation and regression analysis. The results of the study revealed that the general climate dimension of HRD Climate was the most significant predictor of employee engagement followed by the HRD mechanism dimension. Thus, by studying HRD Climate and employee engagement together, this paper makes a significant contribution to the existing dearth of academic literature on employee engagement and HRD Climate in an Indian context.
\end{abstract}

Keywords: HRD, HRD Climate, employee engagement, vigor, dedication.

In the new economy human capital is the foundation for value creation (Becker ef al., 2001). The human capital perspective considers human competencies as one of the most important resources available to the organizations. Various models of HRD 
have been proposed which specify various practices which can help organizations gain a competitive advantage through the accumulation of human capital (DeGeus, 1997; McCracken and Wallace, 1997). According to these models, investment in HRD by organizations and individuals is crucial to build and retain that resource in the future. So, organizations seek to develop employee competencies through sophisticated human resource development strategies (Losey, 1999; Spangenberg, Schroder, \& Duvenge, 1999).

Employee engagement has emerged as one way for organizations to measure their investment in human capital; it is a further alternative to measuring employee commitment to the organization and as a way of creating a more effective workplace (Echols, 2005). In the current economic climate, the employees' psychological connection with their work is certainly a key to compete effectively. The organizations are in need of employees who are engaged with their work (Bakker \& Leiter, 2010). There is substantial amount of research evidence to demonstrate the importance of engagement for bottom line outcomes such as job performance (Bakker \& Bal, 2010; Halbesleben \& Wheeler, 2008), client satisfaction (Salanova, Agut, \& Peiro, 2005), and financial returns (Xanthopoulou, Bakker, Demerouti, \& Schaufeli, 2009b).

With the increasing importance of the employee engagement being highlighted, researchers are now increasingly focusing on what exactly causes employee engagement and how can it be enhanced. However, it is disappointing to see that little research has been undertaken in this direction; identifying the antecedents of employee engagement needs to attract considerably more attention.

\section{Employee engagement}

Employee engagement is a positive, fulfilling, work-related state of mind that is characterized by vigor, dedication, and absorption. Rather than a momentary and specific state, engagement refers to a more persistent and pervasive affectivecognitive state that is not focused on any particular object, event, individual, or behavior. Vigor is characterized by high levels of energy and mental resilience while working, the willingness to invest effort in one's work, and persistence even in the face of difficulties. Dedication refers to being strongly involved in one's work and experiencing a sense of significance, enthusiasm, inspiration, pride, and challenge. Absorption, is characterized by being fully concentrated and happily engrossed in one's work, whereby time passes quickly and one has difficulties with detaching oneself from work (Schaufeli et al., 2002). 
The Chartered Institute of Personnel and Development (CIPD)Annual Survey report (2006) defines engagement in terms of three dimensions of employee engagement: Emotional engagement - being very involved emotionally in one's work; Cognitive engagement - focusing very hard whilst at work; and Physical engagement - being willing to 'go the extra mile' for your employer.

Engagement has been shown to be a unique concept which is positively related to, but is reported to be distinct from, other organizational constructs like organizational commitment, organizational citizenship behavior (Robinson et al.,2004), job involvement (May et al., 2004; Hallberg \& Schaufeli, 2006; Saks,2006), workaholism (Schaufeli et al.,2002).

Some studies have reported job characteristics, perceived organizational support, organizational justice, rewards and recognitions (Saks, 2006) various job (Halbesleben, 2010) and personal resources (self efficacy, optimism etc) (Xanthopoulou et al., 2007) as the antecedents of employee engagement. These studies have focused on the various isolated elements of work environment or the personal resources. However, it could be interesting to see how the overall development climate in the organizations influences the employee engagement. The present study attempts to address this interesting issue and the shortage of research on the antecedents of engagement by exploring the relationship between HRD climate and employee engagement on an Indian sample.

\section{HRD Climate}

In order to be successful in a dynamic and competitive business environment, organizations need to continuously anticipate, innovate and adapt. Only by ensuring the dynamism and growth of its employees can any organization successfully cope with the changes. In such a fast changing technology-oriented world, knowledge is the only source of competitive advantage, and this is embodied in the company's employees. In this context, human resource development has a central role to play in promoting and supporting the development of a learning environment to create and nurture knowledge. HRD efforts are directed towards the release of the human potential in individuals, groups and organizations through learning experiences that result from planned and organized training, education and development activities. The term HRD was first introduced in 1969 by Leonard Nadler. He defined HRD as those learning experiences which are organized for a specific time and designed to bring about the possibility of behavioral change. All the HRD activities of an organization are directed towards the development and 
improvement in the performance of the human resource. For the effective implementation of HRD functions a general supportive climate is required. It is the HRD culture which facilitates effective implementation of HR systems so the development and management of a congenial HRD Climate is a must (Krishnaveni, 2008). The HRD Climate of an organization plays an important role in ensuring the competency, motivation and development of its employees (Patel, 2005). HRD Climate results in the development of both employee competence and commitment (Rao, 1999).

HRD Climate was found to correlate positively with organizational effectiveness and productivity (Jain, Singhal and Singh, 1997). In a study conducted by Rohmetra in 1998, job satisfaction was positively associated with HRD Climate. A positive relationship was reported between HRD Climate and job satisfaction, attitude and role efficacy (Kumar and Patnaik, 2002). Also Krishnaveni and Ramkumar (2006) in their study titled "Impact of developmental climate on individual's behavior in organizations" which reported HRD Climate to be associated positively with the level of role satisfaction of individuals in the organization. Purang in her paper titled "HRD Climate: Comparative analysis of Public, Private and Multinational organizations" reported HRD Climate perception of employees in private and multinational organizations to be significantly better in comparison to public sector organizations (Purang, 2006). No significant difference in the perception of HRD Climate was found between the knowledge workers in an engineering institute and a public sector organization (Rodrigues, 2005). The existence of favorable HRD Climate was reported in a study on private sector undertaking in India (Venkateswaran, 1997). Also Famina (2009) in a research on South Asian public sector organization, Kerala State Financing Enterprise, concluded the overall HRD Climate level to be satisfactory. However, in a study on HRD Climate in a medical hospital in J\&K the HRD Climate was reported to be significantly poor (Mufeed, 2006).

The HRD Climate survey developed by T. V. Rao and E. Abraham has conceptualized HRD Climate under three dimensions of a) general climate, b) OCTAPAC culture and c) implementation of HRD mechanisms. The general climate deals with the importance given to human resources development in general by the top management and line managers. The OCTAPAC items deal with the extent to which openness, confrontation, trust, autonomy, proactivity, authenticity and collaboration are valued and promoted in the organization. Openness is there when employees feel free to discuss their ideas, activities and feelings with each other. Confrontation is bringing out problems and issues in the open with a view to solving them rather than hiding them for fear of hurting or getting hurt. Trust is taking people at their face value and believing what they say. Autonomy is giving freedom to let 
people work independently with responsibility. Proactivity is encouraging employees to take the initiative and associated risks. Authenticity is the tendency on the part of people to do what they say. Collaboration is to accept interdependencies, to be helpful to each other and work as teams. The HRD mechanisms measure the extent to which HRD mechanisms are implemented seriously. These mechanisms include performance appraisal, potential appraisal, career planning, performance rewards, feedback and counseling, training, employee welfare for quality work-life and job rotation (Rao \& Abraham 1986).

\section{Employee engagement and HRD Climate}

The theoretical base of the study draws on the Job-Demand-Resource (JD-R) model (Demerouti, Bakker, Nachreiner, \& Schaufeli, 2001; Salanova et al., 2005; Schaufeli \& Bakker, 2004). According to this model the work environment can be categorized into job demands and job resources which relate differently to well being and attitudinal outcomes (Bakker et al., 2003, 2005; Demerouti et al., 2001; Hakanen ef al., 2006; Llorens et al., 2006; Salanova et al., 2005; Schaufeli \& Bakker, 2004; Bakker \& Demerouti 2007). A large number of studies have shown job resources like autonomy, social support, supervisory coaching, performance feedback, participation in decision making and opportunities for learning, training, professional development, to relate positively with employee engagement (Hakanen, Bakker, \& Schaufeli, 2006; Saks, 2006; Xanthopoulou et al., 2007, Bakker et al., 2003; Demerouti et al., 2001).

For instance, in a study on Finnish teachers, job resources such as job control, supervisory support and good organizational climate were reported to be positively associated with work engagement (Hakanen, Bakker, Schaufeli, 2006). In addition, Bakker, Hakanen, Demerouti \& Xanthopoulou (2007) in a study among Finnish school teachers reported that supervisory support, positive appreciation, collaborative organizational climate, and innovative problem solving correlated positively with engagement. Robinson, Perryman \& Hayday (2004) reported that the employees who have a personal development plan and who receive annual formal performance appraisal have significantly higher engagement levels than those who do not. Lau \& May (1998) suggested that companies with a higher quality of work environment (e.g., opportunity for career growth, a culture of support and openness) tend to have higher profits and business success compared to companies with a poor quality of work environment. Studies have also demonstrated the importance of a climate of trust for positive workplace behaviours and attitudes (Dirks \& Ferrin, 2002). From the above evidence it can be concluded that a favourable HRD Climate no doubt is an important organizational resource which can have a 
significant impact on the engagement level of employees. Thus, building on JD-R model we argue that when employees perceive that their organization provides a climate conducive for their growth and development (which is one of their psychological needs) they are more likely to respond by investing time and energy and by being psychologically involved in the work (Bakker \& Bal, 2010). Thus the work environment has the potential to influence employee engagement levels.

The study has three main objectives:

1). To study the employee engagement level of employees in a number of business organizations.

2). To examine the HRD climate existing in the business organizations understudy.

3). To study the impact of HRD climate and its dimensions on employee engagement.

The three objectives are exploratory in nature and we advance one hypothesis with regard to objective 3 based on the theoretical framework of JD-R model and the above literature review: HRD Climate will relate positively to employee engagement.

\section{Method}

Participants

The target population of the present study was comprised of middle and senior level business executives from select business organizations in India. A total of 85 employees from both public and private sector manufacturing and service organizations of India participated in the study. A total of 100 employees from different organizations were approached out of which 87 responded to the questionnaire. Two of the questionnaires were not found suitable due to incomplete information and hence were removed, resulting in 85 usable responses. The information was collected during Nov 2010 - Jan 2011. The questionnaires were given to the employees taking into consideration their availability and interest to respond the questionnaire. Some of the responses were collected through online questionnaire and email. Average age and average experience of the sample were found to be $31.88 \mathrm{yrs}$ and $6.59 \mathrm{yrs}$ respectively. The sample consisted of 67 males (78.82\%) and 18 females $(21.17 \%$ ) aged between 21 yrs to 50 years (mean=31.88, S.D=7.68). Education levels of sample varied: undergraduates 42 (49.41\%) to postgraduates 43 (50.58\%). The work experience profile of the sample was: less than 5 years $(55.29 \%)$, between 5years - 10years $(20 \%)$ and above 10 years $(24.7 \%)$. 


\section{Measures}

Employee engagement (EE) was measured using the Utrecht Work Engagement Scale (UWES) developed by Schaufeli et al. (2002). The scale consists of three subscales; absorption (six items, e.g., "I am immersed in my work", "When I am working, I forget everything else around me"), vigor (six items, e.g., "At my job I feel strong and vigorous", "When I get up in the morning, I feel like going to work"), and dedication (Five items, e.g., "My job inspires me", "I am enthusiastic about my job"). For the present study Cronbach alpha value for the scale was found to be .80 which is well above the acceptable level of .70. All the 17 items were rated on a 5-point Likert scale ( 1 = strongly disagree, 5 =strongly agree). Since the factor analysis did not result in a clear factor structure, a composite work engagement score was used for regression analysis. This is consistent with the recommendations of Schaufeli et al. (2006) where the total score on UWES was recommended as the indicator of engagement for all practical purpose.

HRD Climate was measured using the 38 items HRD Climate survey instrument by Rao and Abraham (1986). The authors have categorized the scale items under the three dimensions of a) general climate (sample items: "The top management believes that human resources are an extremely important resource and that they have to be treated more humanly", "The top management is willing to invest a considerable part of their time and other resources to ensure the development of employees"), b) OCTAPACE culture (sample items: "People in this organization are helpful to each other", "People trust each other in this organization") and c) HRD mechanisms (sample items: "Employees are sponsored for training programmes on the basis of genuine training needs", "Performance appraisal reports in our organization are based on objective assessment and adequate information and not on favoritism") as defined earlier for the ease of interpretation without losing the explanatory power. The HRD Climate questionnaire uses a five-point scale (almost always true, mostly true, sometimes true, rarely true and not at all true), average scores of 3 and around indicate a moderate tendency on that dimension existing in the organization. Scores around 4 indicate a fairly good degree of that dimension existing in the organization. In order to make interpretations easy the mean scores can be converted into percentage scores using the formula percentage score $=($ Mean Score-1) $\times 25$. This assumes that a score of 1 represents 0 per cent, 2 represents 25 per cent, 3 represents 50 per cent, 4 represents 75 per cent and 5 represents 100 per cent. Thus, percentage scores indicate the degree to which the particular dimension exists in that company out of the ideal 100. In the present study the reliability coefficient of the scale was found to be .88 . 
Results

Employee engagement

The average score of employee engagement was found to be 3.69 (see table1), which indicates the existence of a considerable (above average) level of engagement for the employees in the organizations under study. However there is substantial scope for improvement. This may be because of the low scores on the vigor and absorption dimensions. Out of the three dimensions, dedication was found to have the highest average mean score of 3.85, followed by vigor with average mean score of 3.66 (see tablel). If we go for the item-wise analysis of means "I find the work that I do full of meaning and purpose" scored highest (3.94) and "When I am working, I forget everything else around me" scored the lowest with the average mean score of 3.36 which clearly highlights the high dedication level of executives in relation to their work. Also, these are the items which contributed to the highest score on the dedication dimension and to lowest score on the absorption dimension.

\begin{tabular}{lc}
\hline Variable & Mean Scores \\
\hline Employee Engagement & 3.69 \\
Vigor & 3.65 \\
Dedication & 3.85 \\
Absorption & 3.6 \\
\hline
\end{tabular}

Table 1: Employee engagement

HRD Climate

The average mean score of the HRD Climate was found to be 3.61 (65.25\%) for the organizations under study which is at the moderate level (above average), leaving huge scope for improvement.

\begin{tabular}{lc}
\hline Variable & Mean Scores \\
\hline HRD Climate & 3.61 \\
General HRD Climate & 3.6 \\
OCTAPAC culture & 3.5 \\
HRD Mechanism & 3.73 \\
\hline
\end{tabular}

Table 2: HRD climate 
Of the three dimensions of HRD Climate, the mean average score of "The successful implementation of HRD mechanisms" (3.73) was found to be highest followed by general HRD Climate with mean average score of 3.60 (see table 2). Thus, HRD mechanisms dimension is more prevalent than the other two. Out of the three dimensions of HRD Climate, OCTAPAC culture was found to have the lowest average mean score of 3.48 (62\%). Again if we look at the item-wise analysis of the 38 items of the HRD Climate questionnaire, "The top management believes that human resources are an extremely important resource and that they have to be treated more humanly" was found to have the highest average mean score of 4.01 and "Employees in this organization are very informal and do not hesitate to discuss their personal problems with their supervisors" scored the lowest with the average mean score of 3.28 .

Relationship between HRD Climate and employee engagement

Correlation analysis was performed to determine the relationship between engagement level and HRD Climate in the organizations. Table 3 shows that a significant and positive correlation exists between these two variables ( $r=.669, p<.01)$. Therefore, it makes it clear that higher scores on developmental climate of the organization are associated with higher employee engagement score.

Also from the table 3 it can be seen that HRD Climate correlates positively with all the three dimensions of employee engagement. HRD Climate correlates most highly with the vigor dimension of engagement $(r=.626, p<.01)$, followed by absorption $(r=.591, p<.01)$

From table 3 it can also be noticed that out of the three dimensions of HRD Climate, general climate dimension correlated most highly with employee engagement $(r=.659, p<.01)$, suggesting that the top management and line manager's commitment to development of human resources have the highest potential to influence employee engagement followed by successful implementation of HRD mechanisms $(r=.613, p<.01)$. 


\begin{tabular}{|c|c|c|c|c|c|c|c|c|c|c|}
\hline Variables & Mean & SD & 1 & 2 & 3 & 4 & 5 & 6 & 7 & 8 \\
\hline \multicolumn{11}{|l|}{ 1.General } \\
\hline Climate & 46.84 & 6.53 & $(.768)$ & & & & & & & \\
\hline \multicolumn{11}{|l|}{ 2.OCTAPACE } \\
\hline Culture & 38.35 & 5.83 & $.566^{* *}$ & $(.712)$ & & & & & & \\
\hline \multicolumn{11}{|l|}{ 3.HRD } \\
\hline Mechanisms & 52.29 & 6.26 & $.706^{* *}$ & $.661^{* *}$ & $(.715)$ & & & & & \\
\hline \multicolumn{11}{|l|}{ 4. HRD } \\
\hline Climate & 137.49 & 16.29 & $.876^{* *}$ & $.840 * *$ & $.905^{* *}$ & $(.881)$ & & & & \\
\hline 5.Vigor & 21.92 & 3.51 & $.628^{* *}$ & $.473^{* *}$ & $.532^{* *}$ & $.626^{* *}$ & $(.534)$ & & & \\
\hline 6.Dedication & 19.25 & 2.82 & $.497^{* *}$ & $.301^{* *}$ & $.533^{* *}$ & $.512^{* *}$ & $.544^{* *}$ & $(.537)$ & & \\
\hline 7.Absorption & 21.62 & 3.51 & $.571^{* *}$ & $.430 * *$ & $.539 * *$ & $.591^{* *}$ & $.722^{* *}$ & $.580^{* *}$ & $(.560)$ & \\
\hline \multicolumn{11}{|l|}{ 8.Employee } \\
\hline Engagement & 62.81 & 8.57 & $.659 * *$ & $.472^{* *}$ & $.613^{* *}$ & $.669^{* *}$ & $.891^{* *}$ & $.790^{* *}$ & $.901^{* *}$ & $(.80)$ \\
\hline
\end{tabular}

Note: ${ }^{* *}$ correlation is significant at .01 level (2-tailed), Values in the parenthesis represent the reliability values.

Table 3: Mean standard deviation and intercorrelations of study variables

Impact of HRD climate on employee engagement

From the correlation analysis it was clear that HRD climate relates positively to employee engagement. Now, in order to know how much variance in engagement is explained by HRD climate dimensions a stepwise regression analysis was performed. In the stepwise regression model the order of entry of predictor variables is based solely on statistical criteria. As the authors were unsure about the relative predictive power of the independent variables, stepwise regression analysis was found to be the most appropriate statistical technique (Ho, 2006). Here, statistical regression was accomplished using the backward deletion method, where the equation starts out with all the independent variables entered in the model. Each variable is then evaluated one at a time, in terms of its contribution to the regression equation. Those variables that do not contribute significantly are deleted (Ho, 2006). It can be seen from the table 4 below that $45.9 \%$ of the variation in employee engagement is explained by all the three dimensions together i.e. general climate, OCTAPAC culture and HRD mechanism with $F$ value $=24.79, p<.01$. Since the standardized beta coefficient in case of OCTAPAC culture was found to be insignificant (see table 4), as a part of the procedure it was removed from the regression equation in the second step so as obtain a more parsimonious model. 


\begin{tabular}{llcccc}
\hline Dependent variable & $\begin{array}{c}\text { Independent } \\
\text { variable }\end{array}$ & R square & $\begin{array}{c}\text { Adjusted } \\
\text { R square }\end{array}$ & F-value & $\begin{array}{c}\text { Standardized } \\
\text { Beta value }\end{array}$ \\
\hline Step1: & $\begin{array}{l}\text { General climate } \\
\text { OCTAPAC culture }\end{array}$ & 0.479 & 0.459 & 24.79 & $.443^{* *}$ \\
Work Engagement & $\begin{array}{l}\text { OCTA } \\
\text { HRD mechanism }\end{array}$ & & & & .041 \\
Step2: & General climate & & & & $.273^{*}$ \\
Work Engagement & HRD mechanism & 0.478 & 0.465 & 37.51 & $.295^{* *}$ \\
\hline
\end{tabular}

Note: ${ }^{* *}$ pvalue is significant at .01 level, *pvalue is significant at .05level

Table 4: Stepwise regression analysis with employee engagement as dependent variable and dimensions of HRD Climate as independent variables

In the second step, after excluding the OCTAPAC culture from the regression equation, the predictive ability of the model increased and the adjusted $R$ square value augmented from .459 to .465 in the second step i.e., General climate and HRD mechanisms together explain $46.5 \%$ of the variation in employee engagement with $\mathrm{F}$ value=37.51, $p<.01$. Thus it can be concluded that HRD Climate is a significant predictor of employee engagement and general climate and successful implementation of HRD mechanisms are the most significant dimensions of HRD Climate influencing engagement level of employees.

\section{Discussion}

Thus it is the lack of energy, mental resilience at work, willingness to put extra efforts in one's work, persistence in the face of difficulties and low concentration level of employees in their work which is contributing to the lower engagement level of employees. This might be because vigor and dedication are considered to be the core dimensions of engagement which are just opposites of exhaustion and cynicism, the two core dimensions of burnout (Green, Walkey and Taylor, 1991; Maslach, Jackson, \& Leiter, 1996; Schaufeli \& Enzmann, 1998). In contrast to it, the concept of absorption is more similar to the concept of flow (Csikszentmihalyi, 1990) which according to Salanova et al. (2003) is an outcome of engagement and not its component. Though there is wide agreement on the two core dimensions of engagement - energy and involvement/identification, both of which are present in the Utrecht Work Engagement Scale (UWES; Schaufeli \& Bakker, 2010; Schaufeli et al., 2002) - more research is needed to determine if absorption is a core dimension of employee engagement or just an outcome of it (Bakker et al., 2010). These findings are in congruence with the findings of Mauno et al. (2007) where health care workers were reported to experience less absorption than vigor and dedication. This study also reported that the group of professional workers experienced dedication 
more often than the group of non professionals which provides support for our findings as the target population here is comprised of managers in select business organizations in India.

The fact that the OCTAPACE culture dimension of HRD climate had the lowest score implies a certain lack of openness, collaboration, trust, autonomy, authenticity, proactivity, authenticity, confrontation and experimentation in the organizations under study. However this is in contrast to the findings of a HRD Climate study on 18 Indian manufacturing companies where the OCTAPAC culture dimension was found to have the highest mean score (3.51) followed by HRD mechanism (3.49) and general HRD Climate (3.48) i.e. the OCTAPAC culture dimension was found to be more prevalent than general HRD Climate and HRD mechanisms. Also the total HRD Climate score was reported to be 3.49 for Indian manufacturing organizations (Srimannarayan, 2009). This difference in the scores HRD Climate and its dimensions could be due to the difference in the nature of industries as the present study also included service organizations in addition to the manufacturing firms. The findings of the study are similar to the findings of Mishra \& Bhardwaj (2002) where moderate (62\%) HRD Climate was reported in a research on private sector managers. Also Srimannarayan in a study on HRD Climate in 42 organizations which included manufacturing, service and organizations from IT sector in India reported moderate level of HRD Climate (59.61\%). In this study OCTAPAC culture was reported to have a greater mean scores than the other two dimensions (Srimannarayan, 2008).

In the present study the HRD Climate was found to correlate positively with employee engagement. Also, it explained $44.1 \%$ of the variation in the engagement level of employees. This could be due to the fact that job resources act a source of internal motivation resulting in the satisfaction of an employee's basic needs such as the need for autonomy, competence, and relatedness (Deci \& Ryan, 1985; Ryan \& Frederick, 1997; Van den Broeck, Vansteenkiste, De Witte, \& Lens, 2008). A favorable HRD Climate will foster the learning, growth and development of the employees. A work environment where there is adequate support and commitment of the top management towards the development of the employees and where various HRD mechanisms like performance appraisal, potential appraisal, career development, welfare measures etc. are fairly and successfully implemented will enhance the willingness to dedicate efforts and abilities to achieve work goals (Meijman \& Mulder, 1998). This will ultimately result in an increase in employee engagement levels. To improve the engagement level of employees, an atmosphere of trust and openness should be created where they can freely discuss their problems and ideas with their colleagues and superiors and come out with innovative ways of solving various problems facing the organization. Also providing employees with a platform where 
their weakness and strengths can be identified and appropriate actions taken to enhance their strength and overcome their weakness through proper training and development programs will help having employees more engaged with their work. Performance appraisal and feedback fosters learning and helps to improve performance. Taking care of the career development of employees and providing them with adequate support makes employees realize that the organization is concerned with their growth and development which according to social exchange theory will result in a greater engagement level on their part. This is because the employees feel obliged to respond in kind and repay the organization through their engagement level (Saks, 2006).

The findings of the study are in congruence with many research studies where various job resources i.e. physical, psychological, social and organizational aspects of the job like supervisory support, autonomy, feedback and social climate etc. were reported to relate positively with employee engagement (Bakker \& Demerouti, 2007; Hakanen, Bakker \& Schaufeli, 2006; Xanthopoulou et al., 2007; Bakker et al., 2003; Demerouti et al., 2001, Friedman, 1991; Kremer-Hayon \& Kurtz, 1985). Also Saks (2006) reported perceived organizational and supervisory support to be significant antecedents of employee engagement. Schaufeli and Salanova (2007) suggested that one of the keys for keeping employees engaged is to develop them continually throughout their careers which clearly highlights the importance of a developmental climate for the building an engaged workforce. Also Gruman \& Saks (2010) highlighted the importance of fairness and justice in implementation of performance appraisal process in enhancing the engagement level of employees. This study also reported successful and fair implementation of HRD mechanism to be a significant predictor of employee engagement. The results of the study are supported as well by the findings of a study on NGOs in south India where HRD Climate was found to correlate positively with employee engagement and it also predicted it significantly with $31 \%$ determination.

\section{Managerial implications}

The study was conducted to analyze the impact of human resource development climate on employee engagement. The findings of the study provide support for the assumed hypothesis that HRD Climate will correlate positively and will significantly predict employee engagement. Thus in order to improve the engagement level of the employees, HR departments should attempt to improve the HRD Climate of their organizations specially the support from top management and line managers and through fair and successful implementation of the HRD mechanisms like career 
planning, performance appraisal, training, job rotation and potential appraisal as these two dimensions of HRD Climate were found to most significantly predict employee engagement as shown by the stepwise regression analysis. Fair performance appraisal and feedback should be provided to the employees fostering learning and growth of employees. Appreciating good performance helps boost up the confidence of employees and enhances their motivational level resulting in them giving their heart and soul to work resulting in enhanced engagement levels.

Since the HRD Climate was found to be moderately favorable there is need to improve the HRD Climate in the organizations under study. The OCTAPAC culture dimension of HRD Climate was found to score the lowest implying the need to create a culture of openness, trust, collaboration, autonomy, confrontation. This is shown in a study on school teachers and principals where increase trust in the principal resulted in improved performance, increased identification with school and enhanced engagement (Chughtai \& Buckle, 2009). This highlights the importance trust can play in improving the engagement level and ultimately the business performance. Thus a climate promoting trust and openness should be developed. When analyzing item-wise responses, the statement "Employees in this organization are very informal and do not hesitate to discuss their personal problems with their supervisors" was found to have the lowest mean score (3.28) which clearly has an implication for the managers to improve the communication with the employees and increase their openness so that they can discuss their problems freely with their supervisors without any hesitation or fear. Also the score on the statement "Employees are encouraged to experiment with new methods and try out creative ideas" was found to be low which clearly suggests the need to give more autonomy and freedom to the employees so that they can experiment with their creative ideas which will ultimately result in innovations and better performance of the firm.

\section{Limitations and scope for future research}

Like all other research studies this study is also not free of limitations. First, all the measures were based on self-reports thus causing a concern for common method bias (i.e., bias resulting from shared variance in the measurement that is attributed to the instrumentation rather than to the association between the constructs). Also the present study included only cross-sectional information on the relationships between human resource development climate and engagement. Longitudinal and experimental studies should be undertaken in this direction to establish the cause and effect relationship between the studies variables. The present study analyzed 
the impact of HRD Climate on employee engagement though there are many other variables which may influence the engagement level of employees. Using more variables can also reveal certain interaction effects and the capacity of one variable to moderate the effect of others. Also the study did not control for the effects of demographic variables which can have their role in influencing engagement among workers. So future studies should focus on the role of demographic variables as well. The study considered the impact of only organizational level variables on employee engagement although in the literature personal factors are also found to be significant predictors of various job attitudes and behaviors. Thus a research can be made to study the impact of both the personal, job related variables and the various demographic variables on employee engagement. Also the nature of industries can be varied and sample size increased to improve the generalization of the results. The present investigation only considered the unidirectional relationship between the study variables. However, recent researches have reported the reciprocal relationships between job resources and employee engagement (eg. Xanthopoulou et al., 2009a). Future studies should attempt to test the dynamics of the relationship between HRD climate, and employee engagement in an Indian context and beyond. Again the mechanism underlying the relationship between climate and engagement is not clear, which should be addressed by future research. Thus the scope is wide open for future studies to explore several of the issues which remain unaddressed here.

\section{Conclusion}

The study was carried to examine the impact of HRD Climate and its various dimensions on engagement level of employees. The results of the study showed that both HRD Climate and employee engagement in the organizations under study were at a moderate level. The correlation analysis of the study variables revealed that HRD Climate and all its dimensions were positively and significantly correlated with employee engagement. Of the three dimensions of HRD Climate, general HRD Climate and HRD mechanisms were found to be most significant variables in terms of their impact on engagement as revealed by the stepwise regression analysis. Though these two dimensions are significant in terms of their impact on employee engagement, OCTAPAC culture's impact was found be insignificant. The overall impact of HRD Climate was significant on engagement level of employees. It accounted for $44.1 \%$ of the variation in engagement. This study represents a pioneer effort to study the impact of human resource development climate on the engagement level of employees. Thus this study makes a significant contribution to 
the scarce literature available on employee engagement and human resource development climate in an Indian context.

\section{References:}

Bakker, A. B., \& Bal, M. (2010). Weekly work engagement and performance: A study among starting teachers. Journal of Occupational and Organizational Psychology, 83, $189-206$.

Bakker, A.B. \& Demerouti, E. (2007). The Job Demands-Resources model: state of the art. Journal of Managerial Psychology, 22, 309-328.

Bakker, A.B., Albrecht, S.L., \& Leiter, M.P. (2011). Key questions regarding work engagement. European Journal of Work and Organizational Psychology, 20, 4-28.

Bakker, A.B., Demerouti, E., \& Euwema, M. C. (2005). Job resources buffer the impact of job demands on burnout. Journal of Occupational Health Psychology, 10, 170-180.

Bakker, A.B., Demerouti, E., Schaufeli, W.B. (2003). Dual processes at work in a call center: an application of the job demands-resources model. European Journal of Work and Organizational Psychology 12, 393-417.

Bakker, A. B., Hakanen, J. J., Demerouti, E., \& Xanthopoulou, D. (2007). Job resources boost work engagement, particularly when job demands are high. Journal of Educational Psychology, 99, 274-284.

Bakker, A.B., Schaufeli, W.B., Leiter, M.P., \& Taris, T.W. (2008). Work engagement: An emerging concept in occupational health psychology. Work \& Stress, 22, 187-200.

Becker, B.E., Huslid, M.A., \& Ulrich, D. (2001). The HR Scorecard. Boston, MA: Harvard Business School Press.

Chartered Institute of Personnel and Development (CIPD) (2006) Working Life: Employee attitudes and engagement 2006 Research Report. Employee engagement in the public sector: A review of literature. Scottish executive social research 2007. www.scotland.gov.uk/socialresearch.

Chughtai, A.A. \& Buckley, F. (2009). Linking trust in the principal to school outcomes: The mediating role of organizational identification and work engagement. International journal of educational management, 23, 574-589. 
Csikszentmihalyi, M. (1990). Flow: the Psychology of Optimal Experience, New York: Harper \& Row.

Deci, W.L. \& Ryan, R.M. (1985). Intrinsic motivation and self-determination in human behavior. NewYork: Plenum.

DeGeus, A. (1997). The living company. Harvard Business Review, March-April, 51-9.

Demerouti, E., Bakker, A. B., Nachreiner, F., \& Schaufeli, W. B. (2001). The job demandsresources model of burnout. Journal of Applied Psychology, 86, 499-512.

Dirks, K. T., \& Ferrin, D. L. (2002). Trust in leadership: Meta-Analytic findings and implications for research and practice. Journal of Applied Psychology, 87, 61 1-628.

Echols, M.E. (2005). Invest in people. Leadership Excellence, 22, 20.

Famina, A.S. (2009). OCTAPACE profile and human resource climate in a South Asian Public sector undertaking with special reference on KFSE. Pranjana: The Journal of Management Awareness, 12(2).

Friedman, I.A. (1991). High- and low-burnout schools: School culture aspects of teacher burnout. Journal of Educational Research, 84, 325-333.

Green, D.E., Walkey, F.H., \& Taylor, A.J.W. (1991). The Three-factor Structure of the Maslach Burnout Inventory. Journal of Science Behavior and Personality, 6, 453-472.

Gruman, J. A., \& Saks, A. M. (2011). Performance management and employee engagement, Human Resource Management Review. 21, 123-136.

Hakanen, J. J., Bakker, A.B., \& Schaufeli, W.B. (2006). Burnout and work engagement among teachers. Journal of school psychology, 43, 495-513.

Halbesleben, J. R. B. (2010). A meta-analysis of work engagement: Relationships with burnout, demands, resources and consequences. In A. B. Bakker \& M. P. Leiter (Eds.), Work engagement: A handbook of essential theory and research (pp. 118-131). New York: Psychology Press.

Halbesleben, J. R. \& Wheeler, A. R. (2008). The relative role of engagement and embeddedness in predicting job performance and turnover intention. Work and Stress, $22,242-256$. 
Hallberg, U., \& Schaufeli, W.B. (2006). "Same same" but different: Can work engagement be discriminated from job involvement and organizational commitment? European Journal of Psychology, 11, 119-127.

Harter, J.K., Schmidt, F.L. \& Hayes, T.L. (2002). Business-unit-level relationships between employee satisfaction, employee engagement, and business outcomes: A metaanalysis. Journal of Applied Psychology, 87, 268-279.

Ho, R. (2006). Handbook of Univariate and Multivariate Data Analysis and Interpretation with SPSS. NewYork: Taylor \& Francis.

Jain, V. K., Singhal, K.C. \& Singh, V.C. (1997). HRD Climate in Indian Industry. Productivity, $37,628-639$.

Kremer-Hayon, L., \& Kurtz, H. (1985). The relation of personal and environmental variables to teacher burnout. Teaching and Teacher Education, 1, 243- 249.

Krishnaveni, R. (2008). Human Resource Development: a researcher's perspective. New Delhi: Excel Books.

Krishnaveni, R. \& Ramkumar, N. (2006). Impact of Developmental Climate on Individual's Behavior in the Organization", South Asian Journal of Management. Retreived on July 1 , 2011 from

http://findarticles.com/p/articles/mi_qa5483/is_200601/ai_n21406593/?tag=content;col1 .

Kumar, S. \& Patnaik, S.P. (2002). Human Resource Development Climate and Attributes of Teachers in JNVs. Indian Journal of Training and Development, 32, 31-37.

Lau, R. S. M., \& May, B. E. (1998). A win-win paradigm for quality of work life and business performance. Human Resource Development Quarterly, 9, 21 1-226.

Llorens, S., Bakker, A. B., Schaufeli, W., \& Salanova, M. (2006). Testing the robustness of the job demands-resources model. International Journal of Stress Management, 13, 378391.

Losey, M.R. (1999). Mastering the competencies of HR management. Human Resource Management, 38, 99-111.

McCracken, M., \& Wallace, M. (2000). Towards a redefinition of strategic HRD. Journal of European Industrial Training, 24, 281-90. 
Maslach, C., Jackson, S. E., \& Leiter, M. P. (1996). Maslach burnout inventory manual (3rd ed.). Palo Alto: Consulting Psychologists Press.

Mauno, S., Kinnunen, U., \& Ruokolainen, M. (2007). Job demands and resources as antecedents of work engagement: A longitudinal study. Journal of Vocational Behavior, 70, 149-171.

May, D.R., Gilson, R.L., \& Harter, L.M. (2004). The psychological conditions of meaningfulness, safety and availability and the engagement of the human spirit at work. Journal of Occupational \& Organizational Psychology, 77, 11-37.

Meijman, T.F., \& Mulder, G. (1998). Psychological aspects of workload. In P.J.D. Drenth \& H. Thierry (Eds.), (Eds.), Handbook of work and organizational psychology, Vol. 2: Work psychology (pp. 533). Hove: Psychology Press.

Mishra, M. (1999). Job Satisfaction as a Correlate of HRD Climate (An Empirical Study). Indian Journal of Training and Development, 29, 5.

Mishra, P. \& Bhardwaj, G. (2002). Human Resource Development Climate: An Empirical Study among Private Sector Managers. Indian Journal of Industrial Relations, 38, 66.

Mufeed, S.A. (2006). The need for a focus on key elements of HRD Climate in Hospitalsan Empirical study, Management of Labour Studies, XLRI, 31, 57-65.

Nadler, L (1969). The variety of Training Roles. Industrial \& Commercial training, 1(1).

Patel, M.K. (2005). Case studies on HRD practices. New Delhi: Anmol Publications Pvt. Ltd. Purang, P. (2006). HRD Climate: A Comparative analysis of Public, Private and Multinational organizations. Indian Journal of Industrial Relations, 41, 407-419.

Rao, T. V. (1999). HRD Audit: Evaluating the Human Resource Function for Business Improvement. New Delhi: Response Books.

Robinson, D., Perryman, S. and Hayday, S. (2004). The Drivers of Employee Engagement. Brighton: Institute for Employment Studies

Rodrigues Lewlyn, L. R. ( 2005). Industry-Institute correlates of HRD Climate: Empirical study based Implications. Indian Journal of Industrial Relations, 41, 167-187.

Rohmetra, N. (1998). Towards Creating a Learning Organization: The HRD Climate Focus, Paradigm, 2, 56-63. 
Ryan, R.M., \& Frederick, C.M. (1997). On energy, personality, and health: Subjective vitality as a dynamic reflection of well-being. Journal of Personality, 65, 529-565.

Saks, A. M. (2006). Antecedents and consequences of employee engagement. Journal of Managerial Psychology, 21, 600-619.

Salanova, M., Agut, S., \& Peiro, J.M., 2005. Linking organizational resources and work engagement to employee performance and customer loyalty: the mediation of service climate. Journal of Applied Psychology, 90, 1217-1227.

Salanova, M., Llorens, S., Cifre, E., Martinez, I., \& Schaufeli, W.B. (2003). Perceived Collective Efficacy, Subjective Well-being and Task Performance among Electronic Work Groups: An Experimental Study. Small Group Research, 34, 43-73.

Schaufeli, W. B., \& Bakker, A. B. (2004). Job demands, job resources, and their relationship with burnout and engagement. Journal of Organizational Behavior, 25, 293 315.

Schaufeli, W. B., Bakker, A. B., \& Salanova, M. (2006). The measurement of work engagement with a short questionnaire: A cross-national study. Educational and Psychological Measurement, 66, 701-716.

Schaufeli, W. B., Salanova, M., Gonzalez-Roma, V., \& Bakker, A. B. (2002). The measurement of engagement and burnout: a two-sample confirmatory factor analytic approach. Journal of Happiness Studies, 3, 71-92.

Schaufeli,W., \& Enzmann, D. (1998). The burnout companion to study and practice: A critical analysis. London: Taylor \& Francis.

Schaufeli, W., \& Salanova, M. (2007). Work engagement: An emerging psychological concept and its implications for organizations. In S. W. Gilliland, D. D. Steiner, \& D. P. Skarlicki (Eds.), Managing social and ethical issues in organizations (pp. 135-177). Greenwich, CT: Information Age Publishing.

Spangenburg, H.H., Schroder, H.M., \& Duvenge, A. (1999). A leadership competence utilisation questionnaire for South African managers. South African Journal of Psychology, 29, 117-29.

Srimannarayan, M. (2009). Human Resource development climate in manufacturing sector. Management \& Change, 13(1). 
Srimannarayana, M. (2008). Human Resource development Climate in India. The Indian Journal of Industrial Relations, 44(2).

Venkateswaran, K. P. S. (1997). A note on HRD Climate. Vikalpa, 22, 51-53.

Van den Broeck, A., Vansteenkiste, M., De Witte, H., \& Lens, W., (2008). Explaining the relationships between job characteristics, burnout, and engagement: The role of basic psychological need satisfaction. Work \& Stress, 22, 277-294.

Xanthopoulou, D., Bakker, A. B., Demerouti, E., \& Schaufeli, W. B. (2007). The role of personal resources in the job demands-resources model. International Journal of Stress Management, 14, 121-141.

Xanthopoulou, D., Bakker, A.B., Demerouti, E. and Schaufeli, W.B. (2009a). Reciprocal relationships between job resources, personal resources, and work engagement. Journal of Vocational Behavior, 74, 235-244.

Xanthopoulou, D., Bakker, A.B., Demerouti, E. and Schaufeli, W.B. (2009b). Work engagement and financial returns: A diary study on the role of job and personal resources. Journal of Occupational and Organizational Psychology, 82, 183-200. 


\section{About the authors:}

Richa Chaudhary, MBA (HR \& Finance)

Ms. Richa Chaudhary is currently pursuing Ph.D. from Department of Management studies, Indian Institute of Technology, Roorkee. She has done her MBA from UP technical University. She has work experience in teaching and industry. She has received the Best paper award in a recently held conference at IITM Gwalior, India. Chaudhary has presented papers at many national and international conferences and has attended various workshops on statistical tools and techniques.

Address for correspondence: Richa Chaudhary, Research Scholar, Department of Management studies, Indian Institute of technology, Roorkee, Uttarakhand- 247-667. Email Address: richa.chaudhary18@gmail.com

Dr. Santosh Rangnekar, Ph.D., M.B.A.(HRM), LL.B.(Hons), PGDPM\&IR. Dr. Santosh Rangnekar is working as Associate Professor at Indian Institute of Technology, Roorkee. He has 25 yrs of work experience in both industry and academics. Under his supervision 4 candidates have been awarded Doctorate degree and currently 8 candidates are pursuing PhD.

Dr. Mukesh Barua is working as Assistant Professor at Indian Institute of Technology, Roorkee. He is a mechanical engineer by profession. He obtained his Ph.D. from Indian Institute of Technology, Madras. He has more than 15 yrs of work experience in academics. He has attended many national and international conferences and has published several papers in national and international journals. He has organized a large number of workshops on statistical tools and techniques. He is currently guiding four PhD students. 